\title{
Hidden benefits of public private partnerships: the case of water pressure management in Sebokeng
}

\author{
R S MCKenZIE, W WeGeLIN, P MohaJANEANd and S SHABalaLA*
}

\begin{abstract}
Many water distribution systems in South Africa are deteriorating due to many years of neglect resulting in a serious maintenance backlog. Recent government legislation has introduced free basic water to all South Africans up to a limit of $6 \mathrm{Kl} /$ month per property which in turn causes certain confusion regarding payment among many residents. These key issues and others have led to serious problems with service delivery specifically in the low income areas where the maintenance has been neglected for more than 30 years in some cases. The potential for support from the Private Sector has been highlighted at the highest levels within government as a possible solution to addressing the existing backlogs despite the fact that there are relatively few successful projects to support this view.

This paper presents the results after 30 months of operation of a small scale public private partnership in one of the largest low income areas in South Africa where the Sebokeng/Evaton Pressure Management Project was commissioned in July 2005. The savings both in terms of volume of water saved as well as financial savings to the municipality are impressive and exceed all initial expectations. The most interesting a1 spect of the project, however, is not the savings achieved from the installation, but the numerous other additional benefits that have materialised which were not originally anticipated when the project was commissioned. Such benefits, include the identification of many network problems that had been undetected for more than 9 years as well the sudden interest in helping the residents by several government and semi-government organisations. These organisations were unable or unwilling to provide any support to the area prior to the successful Public Private Partnership.

The project represents a significant advancement in Public-Private Partnerships (PPP's) and clearly demonstrates that small scale Public Private Partnerships can be viable despite the general view that this type of project is confined to large scale initiatives due to the effort and expense in developing the PPP type of contract. The paper provides details of the processes involved in setting up and implementing such a project and highlights that the model used by the Project Team to address leakage in Sebokeng and Evaton can be adapted for use in other areas and other applications to improve service delivery throughout South Africa as well as elsewhere in the world where conditions permit.
\end{abstract}

The paper presents the results from the project after the first 30 months of operation and summarises some of the many additional benefits that have arisen from the project.

Dr RS McKenzie and $\mathrm{Mr} \mathrm{W}$ Wegelin are attached to the consulting firm of WRP Pty Ltd of Brooklyn Square Pretoria, South Africa. They are also, as researchers in the field of integrated water resource management, associated with the Niche Area for Cultural Dynamics at the Vaal Triangle Campus of North-West University in Vanderbijlpark. The co-authors, Messrs P Mohajane and S Shabalala are officials of the Emfuleni Local Municipality. 


\section{Keywords}

Public private partnerships (PPP), water supply infrastructure, Sebokeng, Emfuleni Local Municipality, Rand Water, water supply, water pressure management.

\section{Disciplines}

Civil engineering, hydrology, Public management, Integrated Water Resource Management.

\section{Introduction}

Emfuleni Local Municipality is shown in Figure $\mathbf{1}$ and is located to the south of Johannesburg in the industrial heartland of South Africa. A separate water utility called Metsi-a-Lekoa was established several years ago to manage the supply of potable water to approximately 1.2 million residents of the Municipality of which 450000 are located in the Sebokeng and Evaton areas. Water is supplied to Metsi-a-Lekoa from the local bulk water provider which is one of the largest providers of potable bulk water in the world.

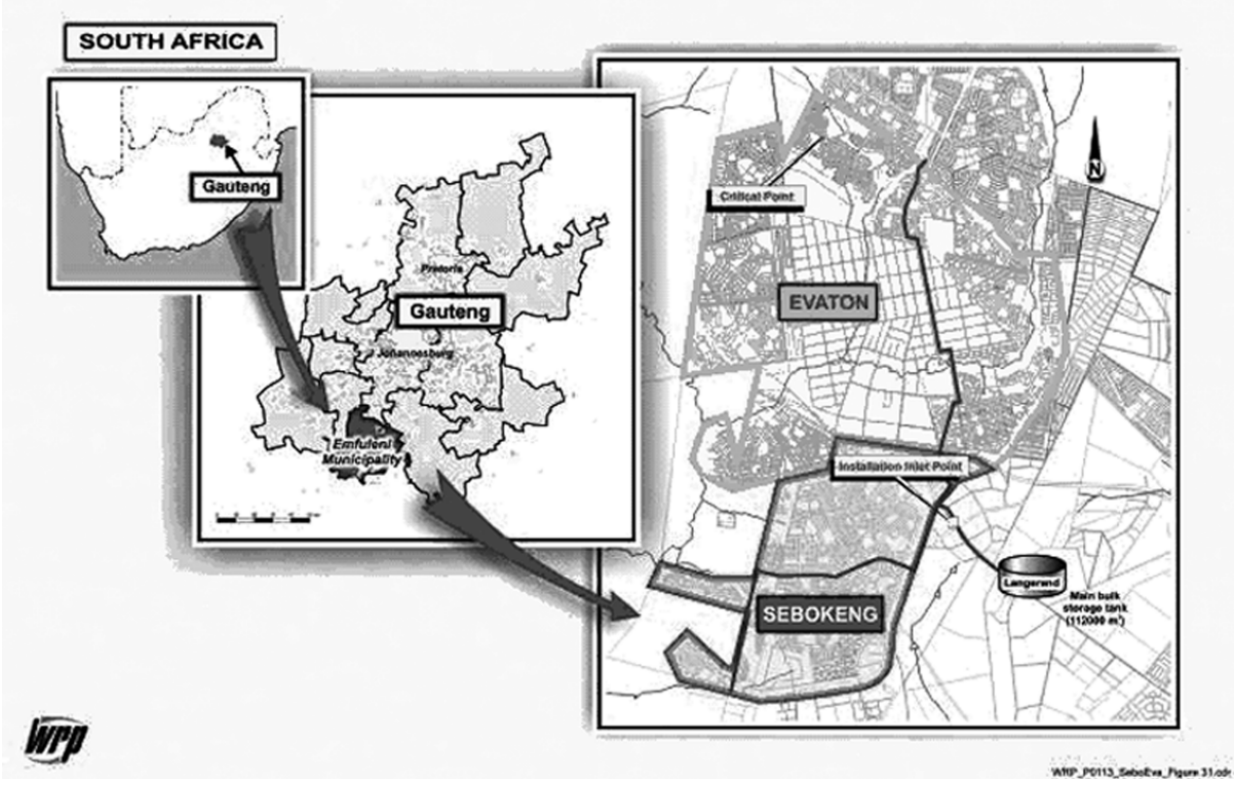

Figure 1: Location Plan 
The areas are predominantly low-income residential areas with approximately 70000 household connections, each of which is supplied with an individual water supply as well as water borne sewage. The combination of low income coupled with high unemployment has resulted in a general deterioration of the internal plumbing fittings over a period of many years causing high levels of leakage. The leakage at the start of the project was known to be extremely high as indicated by a Minimum Night Flow in the order of $2800 \mathrm{~m}^{3} / \mathrm{hr}$ as shown in Figure 2. This is one of the highest Minimum Night Flows recorded anywhere in the world and represents almost two Olympic sized swimming pools of water every hour during a period when demand for water should be minimal. It should be noted that there is virtually no storage in the Sebokeng and Evaton areas, either at bulk reticulation level or domestic property level. The high Minimum Night Flow is therefore almost completely due to leakage, most of which occurs inside the properties and is therefore not evident from normal visual inspection. It should also be noted that since most of the leakage occurs inside the households, the leaking water returns to the sewage treatment plant through the sewer network which is often overloaded to such an extent that spillages of raw sewage into local river courses are a common occurrence in the area.

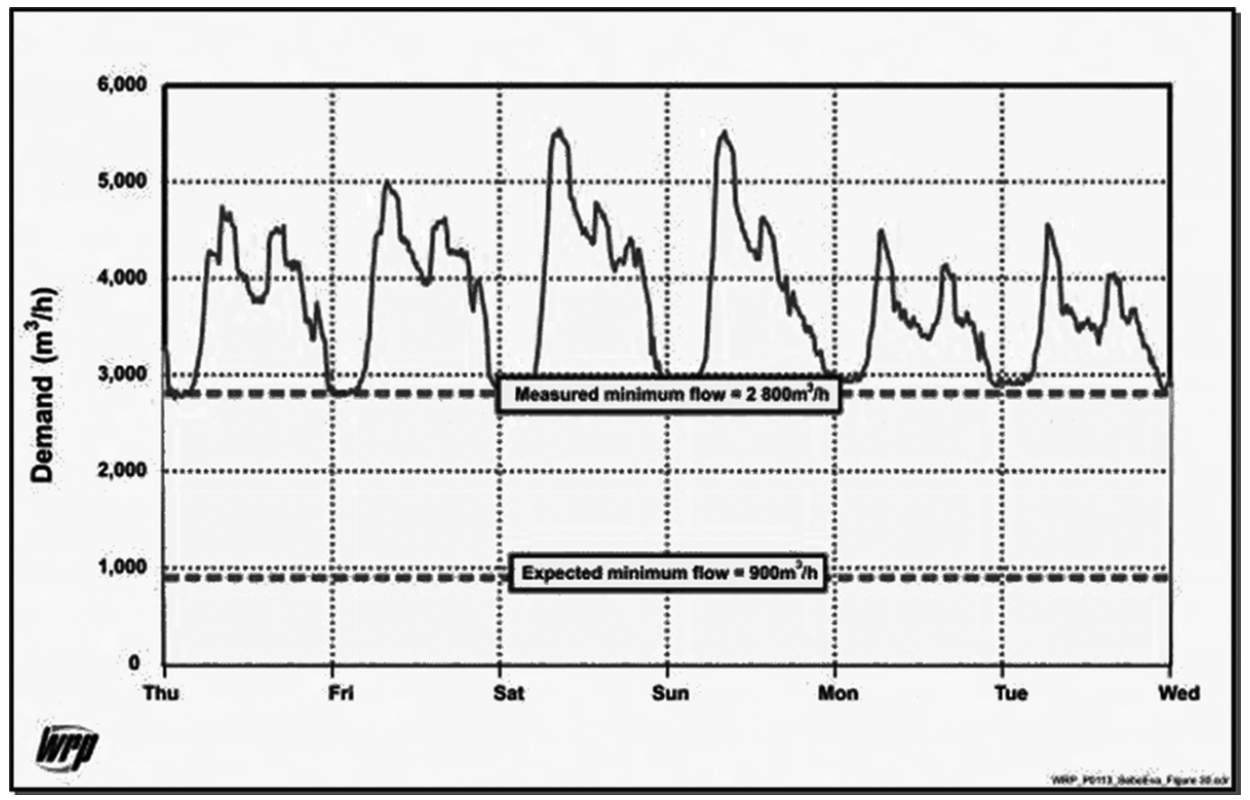

Figure 2: Initial water demands for a 6-day period entering Sebokeng and Evaton in July of 2003 
It was estimated that the wastage in the area before the project was commissioned was in the order of $80 \%$ of the water supplied to the area which in turn represented an annual water bill of approximately R120 million per year ( $\pm \$ 20$ million).

In 2004 the municipality appointed WRP Pty Ltd to design and commission what is understood to be one of the largest advanced pressure management installations in the world as the first phase of a long term strategy to reduce wastage in the area. The project involved no financial input from the municipality and even the initial capital costs were borne in total by the project team. The project was, effectively, a small scale Public Private Partnership (PPP) involving a simple risk-reward model and the original concept is discussed in detail by Mckenzie and Wegelin (2005). It basically reduces water pressure in the area during off-peak periods and in this manner reduces the water lost through leakage.

The concepts of using pressure management to reduce leakage from potable water distribution systems are not new and were first introduced to South Africa from the UK in the mid 1990s. Some details and background to the concepts are provided by Mckenzie (2001) and Mckenzie \& Wegelin (2002). South Africa is now generally regarded as one of the world leaders in pressure management and the scope for large scale pressure management was first established through the commissioning of the Khayelitsha Pressure Management Project in 2000 which is described in detail in numerous national and international publications including Mckenzie (2002), Mckenzie, Mostert and Wegelin (2003) and Mckenzie (2005).

It should be noted that Pressure Management is only one of the many possible Water Demand Management interventions that can be considered when trying to reduce leakage and wastage from a water reticulation system. The leaks are not repaired and will continue to run, albeit at a much lower flow rate. After pressure management has been implemented, it is usually necessary to address the underlying problems using different techniques and in this regard the full range of Water Demand Management techniques should be considered. Details of the various interventions that can be considered are provided in the "Water Demand Management Cookbook" (Mckenzie et al, 2003) which was produced to help water suppliers understand their leakage problems and how to address them.

\section{Benefits of the project}

The most obvious benefits from the project are clearly the savings in water purchases by the municipality from the bulk water provider due to the reduced leakage in the Sebokeng and Evaton areas. The 
initial projected savings of approximately $\mathrm{R} 20$ million ( $\pm \$ 3.3$ million) per year (Mckenzie and Wegelin, 2005) were in fact exceeded and after the first full year of operation the actual savings achieved were closer to R27 million ( $\pm \$ 4.5$ million) as highlighted by Mckenzie and Wegelin (2006). At the time of writing this paper, the project had been operational for 30 months and the initial level of savings had been maintained as shown in Table $\mathbf{1}$ and again graphically in Figure 3.

\begin{tabular}{|c|c|c|c|c|c|}
\hline \multirow[b]{2}{*}{ Month } & \multicolumn{2}{|c|}{ Water Use in m3 } & \multicolumn{3}{|c|}{ Savings } \\
\hline & Expected & Actual & m3 & Rands & USS \\
\hline Jul-05 & $3,130,000$ & $2,438,310$ & 691,690 & $1,909,064$ & 318,177 \\
\hline Aug-05 & $3,140,000$ & $2,460,620$ & 679,380 & $1,875,089$ & 312,515 \\
\hline Sep-05 & $3,048,000$ & $2,459,070$ & 588,930 & $1,625,447$ & 270,908 \\
\hline Oct-05 & $3,159,000$ & $2,406,260$ & 752,740 & $2,077,562$ & 346,260 \\
\hline Nov-05 & $3,066,000$ & $2,421,960$ & 644,040 & $1,777,550$ & 296,258 \\
\hline Dec-05 & $3,178,000$ & $2,427,780$ & 750,220 & $2,070,607$ & 345,101 \\
\hline Jan-06 & $3,188,000$ & $2,337,020$ & 850,980 & $2,348,705$ & 391,451 \\
\hline Feb-06 & $2,887,000$ & $1,997,250$ & 889,750 & $2,455,710$ & 409,285 \\
\hline Mar-06 & $3,207,000$ & $2,200,560$ & $1,006,440$ & $2,777,774$ & 462,962 \\
\hline Apr-06 & $3,112,000$ & $2,118,830$ & 993,170 & $2,741,149$ & 456,858 \\
\hline May-06 & $3,226,000$ & $2,055,280$ & $1,170,720$ & $3,231,187$ & 538,531 \\
\hline Jun-06 & $3,131,000$ & $2,076,990$ & $1,054,010$ & $2,909,068$ & 484,845 \\
\hline Jul-06 & $3,245,000$ & $2,149,000$ & $1,096,000$ & $3,178,400$ & 529,733 \\
\hline Aug-06 & $3,255,000$ & $2,305,861$ & 949,139 & $2,752,503$ & 458,751 \\
\hline Sep-06 & $3,159,000$ & $2,393,860$ & 765,140 & $2,218,906$ & 369,818 \\
\hline Oct-06 & $3,274,000$ & $2,545,230$ & 728,770 & $2,113,433$ & 352,239 \\
\hline Nov-06 & $3,177,000$ & $2,107,670$ & $1,069,330$ & $3,101,057$ & 516,843 \\
\hline Dec-06 & $3,293,000$ & $2,384,830$ & 908,170 & $2,633,693$ & 438,949 \\
\hline Jan-07 & $3,303,000$ & $2,387,810$ & 915,190 & $2,654,051$ & 379,150 \\
\hline Feb-07 & $2,991,000$ & $2,212,620$ & 778,380 & $2,257,302$ & 322,472 \\
\hline Mar-07 & $3,322,000$ & $2,411,900$ & 910,100 & $2,639,290$ & 377,041 \\
\hline Apr-07 & $3,224,000$ & $2,067,000$ & $1,157,000$ & $3,355,300$ & 479,329 \\
\hline May-07 & $3,341,000$ & $2,393,900$ & 947,100 & $2,746,590$ & 392,370 \\
\hline Jun-07 & $3,242,000$ & $2,404,140$ & 837,860 & $2,429,794$ & 347,113 \\
\hline Jul-07 & $3,360,000$ & $2,496,270$ & 863,730 & $2,504,817$ & 357,831 \\
\hline Aug-07 & $3,370,000$ & $2,546,540$ & 823,460 & $2,388,034$ & 341,148 \\
\hline Sep-07 & $3,270,000$ & $2,732,270$ & 537,730 & $1,559,417$ & 222,774 \\
\hline Oct-07 & $3,389,000$ & $2,500,200$ & 888,800 & $2,577,520$ & 368,217 \\
\hline Nov-07 & $3,289,000$ & $2,527,910$ & 761,090 & $2,207,161$ & 315,309 \\
\hline Dec-07 & $3,408,000$ & $2,465,850$ & 942,150 & $2,732,235$ & 390,319 \\
\hline Total & $96,384,000$ & $70,432,791$ & $25,951,209$ & $73,848,416$ & $11,592,557$ \\
\hline
\end{tabular}

Table 1: Summary of water and financial savings for first 30 months of operation

The savings achieved in the first 30 months of operation of the installation exceeded all expectations of both the project team as well as the municipality and are the most obvious benefits to accrue from the project. After operating and managing the installation for two years, several other benefits also became apparent which were not 
initially anticipated. In particular the following benefits have been achieved each of which will be discussed in turn:

- Defer upgrading of infrastructure

- Identification of bottlenecks in the system and problem infrastructure;

- Identification of bulk meter errors;

- Catalyst for funding;

- Improved municipality status;

- Creation of national WDM fund;

- Catalyst for other WDM interventions; and

- Sustainability of savings.

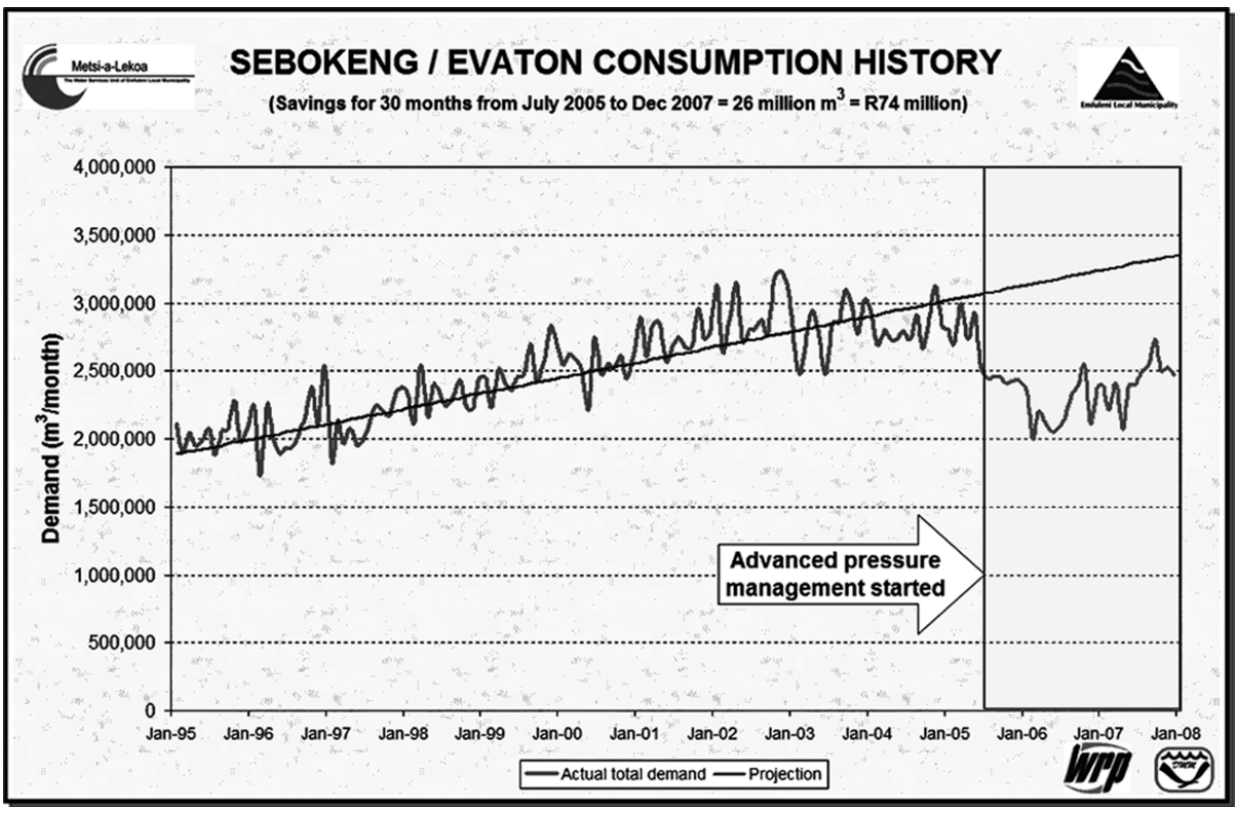

Figure 3: Historical water consumption in Sebokeng and Evaton areas for a 13 year period

\section{Defer upgrading of infrastructure}

With the implementation of the advanced pressure management system the water demand was reduced to 1997 figures as can be seen in Figure 3. The reduced water demand also had a significant impact 
on the sewer flows entering the treatment plant which reduced from $2500 \mathrm{~m}^{3} / \mathrm{h}$ (July 2003) to $1800 \mathrm{~m}^{3} / \mathrm{h}$ (July 2005) as shown in Figure 4. As a result of the project the project the client has gained a reprieve of at least ten years on the upgrading of the water supply and sanitation infrastructure. The reduced pressures have also resulted in a significant reduction in the number of bursts experienced in the area which in turn will prolong the life of the infrastructure.

\section{Identification of bottlenecks in the system}

Under normal circumstances with large scale pressure management projects, the system pressures are gradually reduced during the offpeak periods to ensure that some minimum level of service is achieved at the critical point in the system which is the point experiencing the lowest pressure at the time. The critical point can usually be identified from the reticulation layout drawings or from a hydraulic model of the system if such a model is readily available. The critical point is then monitored continuously as the pressure management activities commence.

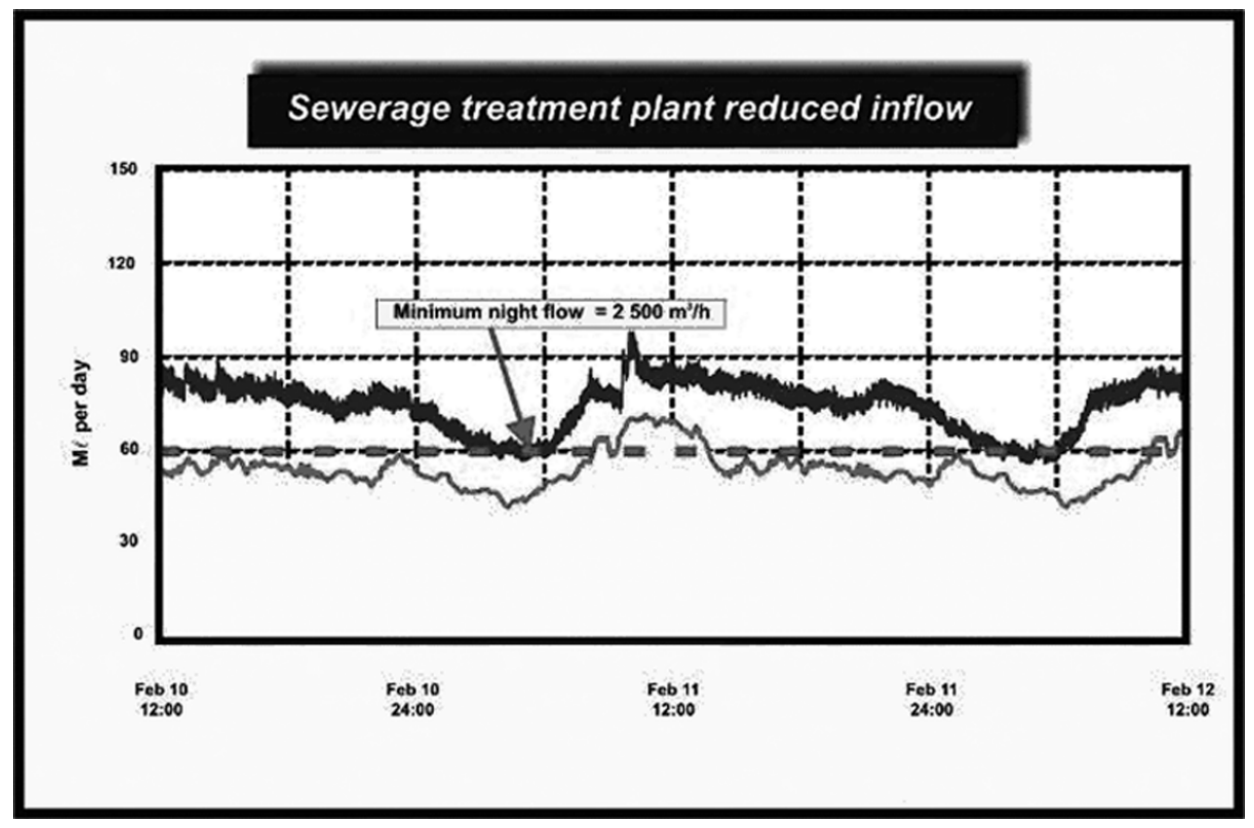

re 4 : The effect of water pressure reduction on sewer return flows for a 48 hour period 
In the case of the Sebokeng/Evaton project, the above process did not proceed to plan and numerous communities complained of low water pressures in areas which theoretically should have had no problems.

On closer examination of the unexpected problem areas, it was found that many of the problems were caused by poor maintenance or inappropriate operation of various boundary valves and/or control valves. In many cases, the boundary valves were left in a semi-open position due to the fact that the operations staff did not know if they should be open or closed.

The operations staff also had the habit of closing sections of pipe in cases where a burst had occurred instead of repairing the burst and reopening the pipeline. This has caused serious bottlenecks in the system which only became apparent when the pressures were lowered. In each case the project team had to cease all further pressure reduction activities and undertake a full investigation involving significant field work to identify and correct all problem valves and/ or sections of pipeline in a particular area. Following the corrective measures, it was normally found that the overall level of service to the specific community improved significantly when the system was reinstated to its original configuration.

\section{Identification of problem infrastructure}

In addition to the identification of bottlenecks as discussed previously, there were numerous cases where serious problems were found in the basic reticulation infrastructure. One of the most common problems identified was that of "missing" pipes or connections. In several cases it was found that connections from smaller pipes (200 $\mathrm{mm}$ or less) had not been made to the bulk mains running through a particular area. In one case, it was found that of the 4 connections shown on the "as-built" plans, only one had in fact been commissioned.

The remaining three connections were sealed with a blank flange plate just before the connection point. In this instance, the community of approximately 3000 residents had been experiencing intermittent supply (water available only during the night-time periods) for almost nine years and had stopped complaining many years ago since nothing was ever done to alleviate the problem. On excavating the three mystery connections and adding the necessary T-pieces (see Figure 5), the area was restored to full system pressure on a 24-hour basis for the first time.

Although the additional connections actually increased the water use in the one problem area, it allowed the pressure to the whole of Sebokeng and Evaton to be lowered during the off-peak periods which 
more than made up for any small local increase in use during the remaining periods.

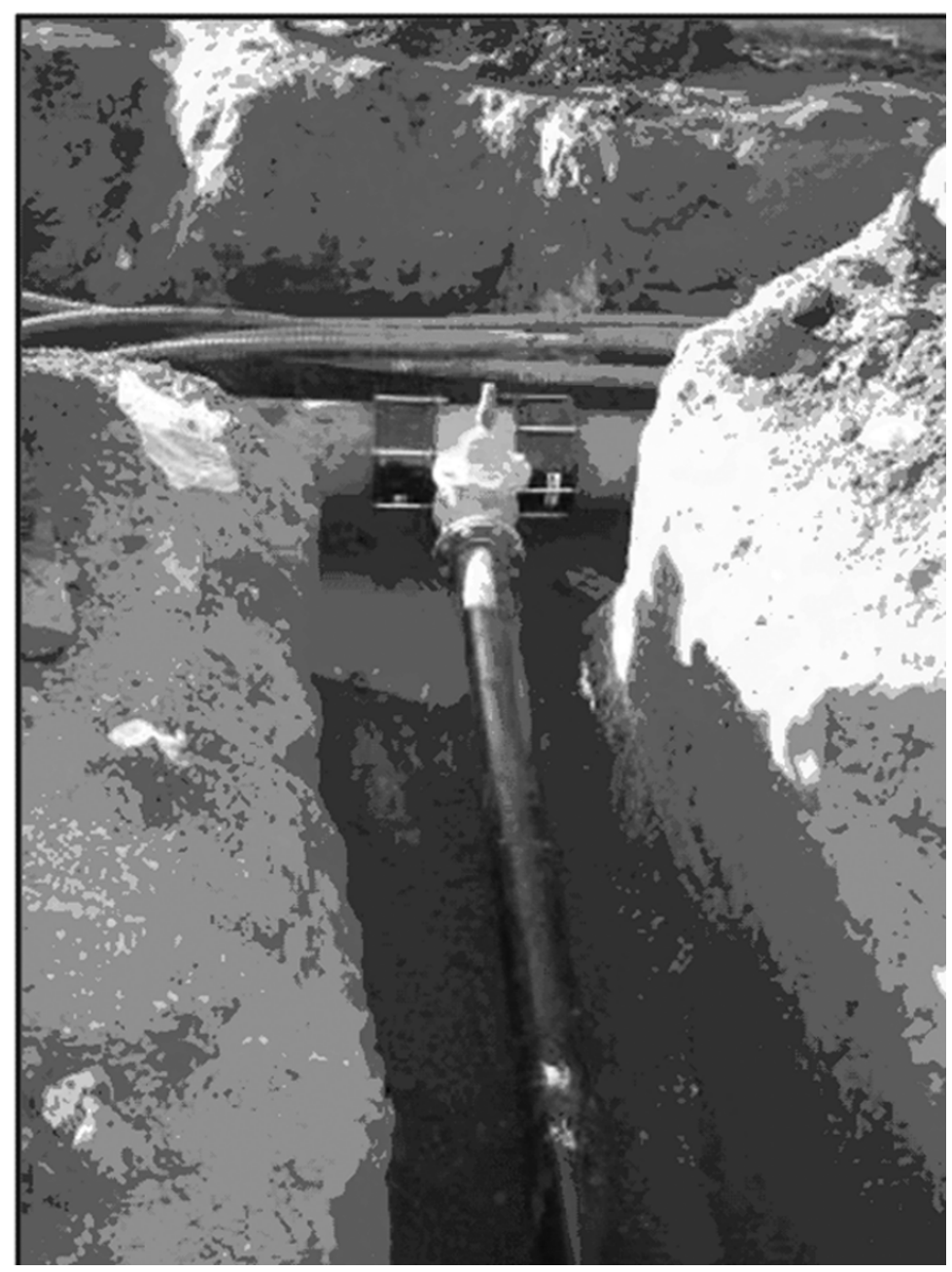

Figure 5: Installation of missing "T-Piece" in Sebokeng

The other key problem identified with the infrastructure was the identification of "missing" valves which were not shown on any reticulation drawings but were thought to exist by the project team due to the manner in which the system was responding to the water pressure. 


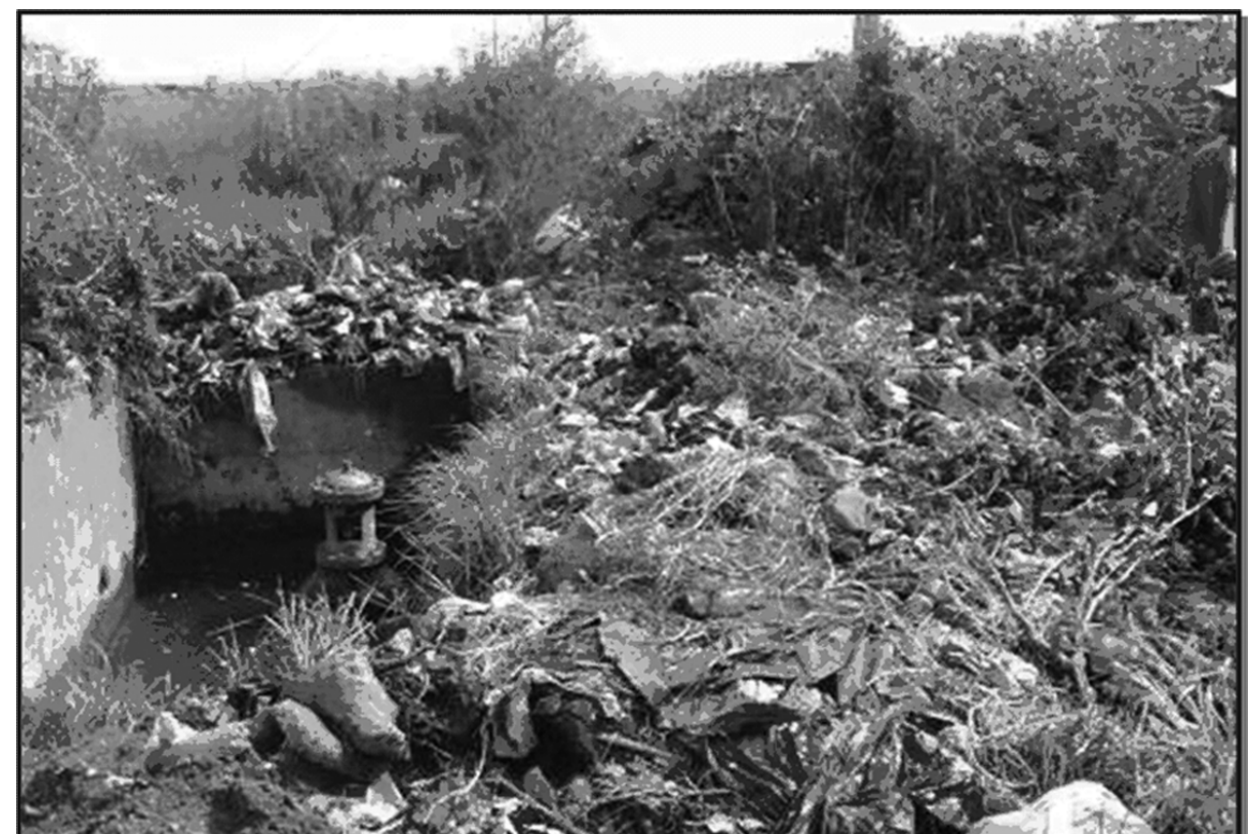

Figure 6: Identification of missing valve and chamber after cleaning

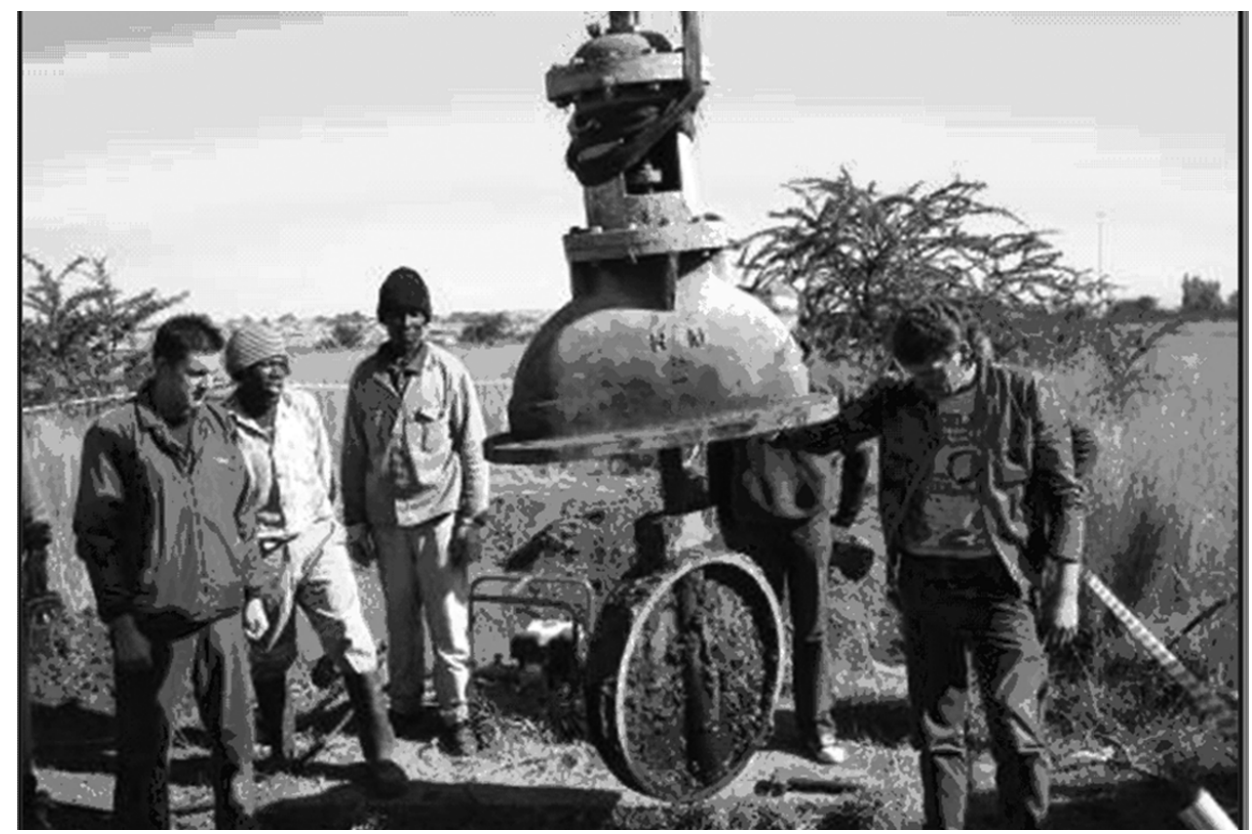

Figure 7: Removal of valve body 
As can be seen in Figure 6 and Figure $\mathbf{7}$ the valve chamber had been buried with rubble and rubbish for approximately 30 years and when the valve was eventually unearthed, it had seized completely. In many cases, the valves are more than 60 years old and must be removed completely and refurbished in order to restore the reticulation system to its normal operating condition. This type of problem has been a common occurrence and it is anticipated that more than 100 large valves similar to that shown in Figure 7 will have to be refurbished. Further details of the project and the problems experienced can be found in various papers which have been presented internationally by the project team including, Mckenzie et. al. (2007), and Siqalaba et al (2006).

\section{Catalyst for funding}

Prior to the implementation of the project, the municipality was unable to access any funding for WDM activities of any nature and even the various "development" banks were unwilling to provide funding for the project. Once the project had been completed, however, and the results were published, the situation changed dramatically and suddenly there were several organisations (including the bulk water provider) wishing to invest funding into Sebokeng and Evaton. One of the main supporters of the project is now the Department of Water Affairs and Forestry (DWAF) which is the national custodian of all raw water in the country and also fulfils the role of regulator countrywide. After assessing the savings from the Sebokeng/Evaton pressure management initiatives, DWAF realised the value of such projects and created a new budget to help overcome the funding difficulties that originally threatened to halt the project. Approximately R50 million ( $\pm \$ 8$ million) has been allocated for 2007 and if successful, the budget will be increased in future to encourage WDM activities throughout South Africa. Of the R50 million $( \pm \$ 8$ million) allocated to WDM activities by the Government, more than R10 million ( $\pm \$ 1.7$ million) has been allocated to support WDM activities in Sebokeng and the surrounding areas.

In addition to the injection of DWAF funding, the municipality itself is now in the position that it has surplus funds for the first time as a result of the R30 million ( $\pm \$ 5$ Million) savings made during the first year of operation. Approximately R10 million ( $\pm \$ 1.7$ million) from the savings has been returned to the water utility to match the DWAF funding which brings the total funding available to upgrade the system for 2007 to more than R20 million ( $\pm \$ 3.4$ million). Prior to the project, the municipality had virtually no budget for maintenance of the system since all funds were being used to support the water account from the bulk supplier. 


\section{Improved municipality status}

Prior to the project, the only publicity received by the municipality was usually with regard to spills of untreated sewage in the Vaal River. Such spills were due in part to the poor infrastructure of the multiple sewage pumping stations and in part to the huge sewage inflows which in turn were caused to a large extent by high internal household leakage.

Since the project has been completed, it has created significant positive publicity for the Municipality and has picked up no fewer than four national awards for technical engineering excellence. The publicity surrounding the project has created awareness at the highest levels in government and the project has been acknowledged in parliament by the water portfolio committee as a model which should be repeated throughout South Africa wherever conditions permit.

The positive exposure from the project has also created a general atmosphere of success within the municipality and the municipal managers who supported the project have also been able to promote their own personnel through various radio and television interviews on the project. In effect, the project has created a turning point within the municipality and the general perception of the municipality has changed from negative to positive.

\section{Catalyst for other WDM interventions}

Perhaps one of the most important benefits to arise from the project is the fact that it has demonstrated what can be achieved with relatively little funding and combined support from both the private and public sectors. Following the successful completion of the project, the Municipal managers have since been able to motivate for and gain approval for several additional technical and social WDM interventions.

Of particular note are the following:

- Sectorisation to enable proper management of the reticulation system -

- $\quad$ Consumer metering and billing as a first step to proper billing;

- Community awareness with particular reference to garden watering;

- $\quad$ Pressure management at district level (<3000 properties) to gain further savings in low lying areas;

- Continuous monitoring of control points to assist with system management; and 
- Development of an asset register as first step to full asset management system.

\section{Sustainability of savings}

One of the key problems to many WDM interventions is the problem of maintaining the initial savings after the project has been completed and the project team has been paid for its efforts. In the case of the Sebokeng/Evaton PPP, the Project Team is responsible for all maintenance and operation for a period of at least 5 years. Since the Project Team receives payment in accordance with the savings generated (up to an agreed limit after which $100 \%$ returns to the municipality) it is essential that the project continues to operate properly until such time that the municipality takes over or extends the period of the contract.

The percentage of the overall savings retained by the Project Team is approximately $15 \%$ based on the first two years of operation and is sufficient motivation for the team to ensure that the project is fully functional at all times. In this manner, the savings initially achieved are still being achieved several years after the project was completed.

It should be noted that the similar project in Khayelitsha is also continuing to provide the savings although it is being operated and maintained by the City of Cape Town (see paper by Mckenzie, Mostert and de Jager, 2004). This highlights that under certain circumstances, it is not essential for the project team to operate and manage the project as is currently the case with the Sebokeng project. Unfortunately very few municipalities have the capacity to operate and manage such a project and the City of Cape Town is more the exception rather than the rule.

The lack of capacity is becoming a serious problem throughout most parts of South Africa and it is anticipated that more Public Private Partnerships involving a relatively long period for operation and maintenance will be implemented. Obviously any Municipalities that have managed to retain a certain level of skilled personnel can implement such projects without any support from the Private Sector, however, the majority no longer have any engineering expertise at all as recently highlighted by Lawless (2008).

This is one of relatively few WDM projects where the savings are audited carefully on a continuous basis and this is considered one of the key elements of a successful WDM project. 


\section{Conclusions}

While the Sebokeng and Evaton Public Private Partnership is clearly one of the most successful small scale PPP's to be completed in South Africa, the real benefits of the project are only now materialising several years after the project was commissioned.

As a result of the significant savings in water purchases from the bulk water provider, the municipality has been able to allocate funds for maintenance of the water distribution system for the first time in several years. In addition to the R10 million allocated by the Emfuleni Local Municipality, the Department of Water Affairs and Forestry also allocated a further R10 million to show support for the efforts. It is likely that these budgets will be doubled for the 2008 to 2009 financial year which clearly highlights the value of the project to the municipality and government.

Due to the availability of the additional funding, many new initiatives have been implemented which could not have been considered before the Public Private Partnership had been commissioned. Some of the other initiatives are discussed in the paper by Siqalaba (2006) which highlights many of the softer issues such as community awareness and schools education which have been addressed over the past 2 years. It is clear that such issues are extremely important and that without proper consultation with the community even the best planned technical interventions will fail.

It is clear that although the financial savings generated exceed all initial expectations, the hidden and often less tangible benefits greatly outweigh the obvious and tangible benefits.

\section{References}

Lawless, A., 2008 "Civil Engineering - the critical profession for service delivery." Civil Engineering, Volume 16 Number 1, January 2008. Pages 26 to 29.

Mckenzie, RS., Wegelin, W., Mohajane, P., and Shabalala, S., 2007a "Hidden benefits of small scale performance based Public Private Partnerships." Proceedings from the International Water Association Specialist Conference: Leakage 2007, Bucharest, Romania, September 2007.

Mckenzie, RS and Wegelin, W., 2006 "Small-scale South African PPP delivers pressure management success." Water 21 Magazine of the IWA, December 2006, pp 20-23.

Mckenzie, RS \& Wegelin W.,2005 “Sebokeng/Evaton Pressure 
Leakage Reduction: Public Private Partnership." Proceedings from the International Water Association Specialist Conference: Leakage 2005, Halifax, Nova Scotia, Canada. pp 382-391. 12 14 September 2005.

Mckenzie, R., 2005 "Pressure Management: Overview of Activities in South Africa." Paper presented at the International Water Association Specialist Workshop, Radisson Resort, Gold Coast, Queensland Australia. 24 February 2005.

Mckenzie, R, Mostert,H and De Jager, T., 2004 "Leakage Reduction Through Pressure Management in Khayelitsha: 2 Years Down the Line." Paper presented at the 2004 Biennial Water Institute of South Africa Conference, ICC, Cape Town, 3 - 5 May 2004.

Mckenzie, R, Buckle, H, Wegelin, W and Meyer, N., 2003 "Water Demand Management Cookbook." Manual on WDM produced for the UN Habitat and Rand Water, ISBN 0-620-30734-X, November 2003.

McKenzie, R., Mostert, H and Wegelin, W., 2003 "Leakage Reduction through Pressure Management in Khayelitsha, Western Cape: South Africa." Paper presented at the Australian Water Association Annual Conference, Perth, 7-10 April, 2003.

McKenzie, R., 2002 "Khayelitsha: Leakage Reduction through Advanced Pressure Control." Journal of the Institution of Municipal Engineering of South Africa, Volume 27, No 8, pp. 43 47 August 2002.

McKenzie, R., 2001 "Development of a pragmatic approach to evaluate the potential savings from pressure management in potable was distributions in South Africa": PRESMAC. Report TT152/01 published by the South African Water Research Commission, July 2001. ISBN No. 1868457222

Siqalaba, Z, Mckenzie,RS, and Kekana, C., 2006 . "Reducing Water Wastage in Sebokeng." Paper presented at the IMESA Annual Conference, Soweto, 11 to13 October 2006.

Wegelin, W and McKenzie, R., 2002 "Leakage Reduction through Pressure Management: Concepts and Case Studies." Report TT $186 / 02$ published by the South African Water Research Commission, August 2002. ISBN No. 1868458326 